\title{
School Stuff: A Pedagogical Regime of Enunciation?
}

[Post print]

\section{Lut Vanden Buverie ${ }^{\mathrm{a}}$}

Laboratory for Education and Society, University of Leuven, Leuven, Belgium Maarten Simons ${ }^{\mathrm{a}}$

Laboratory for Education and Society, University of Leuven, Leuven, Belgium

${ }^{a}$ Vesaliusstraat 2 bus 3761, 3000 Leuven, Belgium

Corresponding author. Telephone: 003216325851.

E-mail: lut.vandenbuverie@kuleuven.be

To site this article: Vanden Buverie, L. \& Simons, M. (2016). School Stuff: a pedagogical regime of enunciation? Pedagogy, Culture and Society. [first online article].

To link to this article: $h$ htp://dx.doi.org/10.1080/14681366.2016.1229689 


\title{
School Stuff: A Pedagogical Regime of Enunciation?
}

\begin{abstract}
A large amount of ethnographic research is conducted in schools. Yet, little is known about the particularity of the school, about what makes the school as a school different from other (learning) environments. As school ethnographies focus primarily on the perspectives and interpretations of pupils and teachers, the school itself - as it happens on a daily basis - remains largely ignored. Drawing on ethnographic research within six Flemish secondary schools, the particularity of the school is examined through its possible regime of enunciation.

By focussing on both sociomaterial and discursive elements within school practices, we look for markers which point at a specific pedagogical regime of enunciation within these practices. Attention is then paid to the manner of speech, to the elements at stake when sayings occur, to the knitting together of objects, time(s) and space(s) as they are enacted through and as part of practices at school.
\end{abstract}

Keywords: school education, ethnography, sociomateriality, regime of enunciation, school practices

\section{Introduction}

The school is more than a place where humans, like pupils and teachers, come together and communicate with one another. It is more than a place where particular human (sub)cultures develop and conflict with one another. However, and as pointed out by several scholars (Nohl 2011; Roehl 2012a; Röhl 2013), when considering the majority of school ethnographies, human communication and human culture seem to be what the school is predominantly about. And yet, as Roehl (2012a) and Mifsud (2014) state, the school is also a place full of objects: pupils sit at chairs, chalk is needed to write on the blackboard, a pencil is used to copy the subject matter in a textbook, wrecked cars are reassembled, wood is handled. Although these and other objects are an inherent part of what constitutes a school, they are often neglected within ethnographic accounts of 'life in school' . Referring to its etymological origin - 'writing about people' ethnographers have predominantly studied the school from the perspective of its inhabitants: pupils, teachers, headmasters, administrative staff and/or parents. As attention is almost exclusively focussed on the social and symbolic dimension of schooling, the material dimension of school life often remains unnoticed (Nohl 2011; Roehl 2012a; Röhl 2013).

Following various scholars like Nespor (1994), Sørensen (2009) and Röhl (2013; see also Roehl 2012a, 2012b), we try to move beyond - what Roehl (2012a) calls - the humanist bias in ethnographic research to broaden our understanding of what the school is about. Objects are then not considered as part of a static background against which pupils and teachers act. Nor are they considered as dead material waiting to be picked up and used by humans. Instead, we consider objects as both acting upon humans and being acted upon by humans. Closely

\footnotetext{
${ }^{1}$ Referring to a book edited by M. Hammersley and P. Woods (1984) which collects significant contributions to the field of pupil ethnography.
} 
interwoven and actively shaping one another, both subjects and objects do (trans)form, interrupt, alter and suspend happenings taking place in schools.

Although school ethnographies from a humanist perspective have extensively fostered our understanding of school life, this paper will not explore the perspectives of the school's inhabitants. Instead, we will study school ${ }^{2}$, how it is done and what might be particular about it. By taking into account material and social elements, we present a sociomaterial perspective to tell something about what it is that makes the school a school, about that which makes the school different from other learning environments, about its own specificity.

After reviewing school ethnographies which start from a humanist perspective, an ethnography of practices is presented in which school practices are understood as incessantly evolving (dis)connections of human and nonhuman elements and the sayings that occur as part of and through these (dis)connections. On the basis of ethnographic fieldwork conducted in six Flemish secondary schools, this paper explores whether indications exist to consider the school from the perspective of a distinct regime of enunciation.

\section{School Ethnography}

Since the 1970s, a considerable amount of ethnographic research has been conducted in schools (Hammersley 1990. See also Ball 1981; Hargreaves 1967; Willis 1988). Hence, it seems reasonable to expect that something is revealed within these studies about what makes the school a school, about its specificity. And it does, although it focusses predominantly on 'life in school' from the perspective of its inhabitants. Only recently, attempts have been made to investigate 'life of school', considering both social and material elements.

\section{Life in School}

As ethnographic studies broaden their research field to include classrooms, the amount of research concerned with school education increases significantly in the $1970 \mathrm{~s}^{3}$. Predominantly influenced by symbolic interactionism, these ethnographic accounts are concerned with the various and complex perspectives and activities of teachers and pupils. As the main research interest lies in the identification of social meaning and the manner in which teachers and pupils make sense of themselves and others, pupils' and teachers' experiences become a major topic within school ethnographies (Hammersley 1990).

Interested in working class culture, Willis (1988) for example, examines the school through the eyes and words of 'the lads', a group of working class pupils within an inner-city English school. As Willis (1988) focusses on the construction of a counter-school culture through the 'guerilla war' like resistance of the lads, the school emerges as consisting of a specific teacher paradigm in which knowledge is extremely valued and holds the promise of qualification and

\footnotetext{
${ }^{2}$ Inspired by Mol (2002) who ethnographically studied the disease 'atherosclerosis'.

${ }^{3}$ As an extensive review of school ethnographies is beyond the scope of this article, a selection of ethnographies is made on the basis of their prevalence within the field of school ethnography.
} 
respect. In recognizing and resisting this dominant paradigm, the lads reveal the school's hidden curriculum which privileges middle-class kids. Although the lads are far more aware of the school's hidden curriculum, in rejecting it, they also reject the promise of upward mobility and subsequently perpetuate their existing class position (Gordon 1997; McFadden and Walker 1997). When studying the organization of classroom talk, Hammersley (1990) for example, focuses on the manner in which a teacher behaves in order to organize pupil participation and on how that specific organisation is relevant for the intelligence pupils are expected to show. Throughout the analysis of classroom interaction, the school appears as an institution of selection and socialisation. To succeed, pupils need to be acquainted with certain teaching conventions and need to be "socialized into a world in which knowledge is something known by those "in authority" and which can be learned only by taking heed of "authorities" (Hammersley 1990, 51).

Starting from symbolic interactionism, the school predominantly emerges throughout the perspectives of pupils and teachers involved. As Hammersley $(1984,4)$ points out, attention is foremost paid to 'how participants actively make sense of their environments, construct and preserve their identities and interest, how they negotiate joint action'. Throughout such ethnographic accounts, the school has come to be known as a place of human culture and communication.

Within a more phenomenological approach of interactionist theory, various scholars, like Keddie (1972), have tried to move beyond the experience of pupils and teachers to focus on the 'taken-for-granted' nature of school reality, and hence, on the defining processes within the school itself. Throughout observations, tape recording and a questionnaire in one comprehensive school, Keddie shows how teachers' perceptions of pupils' ability determine what is taught and learned. School tracking is then no longer an objective given. Instead, it defines what a teacher knows about pupils and therefore enhances or limits the access to academic and abstract knowledge and learning opportunities, usually, to the disadvantage of non-middle class pupils. Keddie then states that 'so-called' objective realities, like school tracking, are not so much based on ability but are a socially constructed framework 'which differentially values and rewards certain types of knowledge' (Turner and Mitchell 1997, 29). Ball (1984) too examines school organisation within a secondary school and records how pupils within different bands are treated differently based upon the assumptions teachers have about their abilities. Hence, throughout band stereotypes in teachers' perception and their behaviour towards different bands, pupils' attitudes towards school values and their academic performances differentiate at the expanse of working class kids.

Hence, both Keddie and Ball reveal the effect of school tracking on teachers' expectations and pupils orientations towards school achievement. Thereby, both scholars emphasize the importance of school organisation when considering the school. Nevertheless, the school remains a strictly human affair as it continues to be understood as an interpersonal process, as socially constructed. 


\section{Life of School}

Although school ethnographies from a rather humanist perspective have extensively fostered our understanding of 'life in school', they did not always reveal much about 'life of school'. For the school is only considered through the interpersonal, the local meanings and perspectives as they are constructed in face-to-face interaction. The school, then, seems to appear merely as a context in which its inhabitants make sense of themselves and others, as a context in which human culture and communication flourishes. In line with Mol $(2002,5)$, it can be stated that the school thus appears as 'a single passive object (...) waiting to be seen from the point of seemingly endless series of perspectives'. To move beyond this 'endless series of perspectives' and to find a way in which the school itself can be studied, an ethnography of practices is more adequate as suggested by Mol. Such an ethnography does not search for local meaning constructed in face-to-face interaction. Instead, it is interested in the activities, events and relations through which the school, as a set of specific practices, occurs at a daily basis. In turning towards the happenings of the school, attention is shifted from pupils' and teachers' experiences about the school to day-to-day events involving pupils and teachers, but also chairs and tables, textbooks, blackboards, gestures and words.

In order to describe and grasp these everyday school events, several educational scholars like Nespor (1994), Sørensen (2009), Nohl (2011) and Roehl (2012a; Roehl 2012b) have taken a sociomaterial stance and consider school education as inherently social and material. Starting from the idea that human acting is inevitably also interacting with nonhumans or materials, Nespor (1994) shifts focus from individuals and groups in face-to-face interaction to question how activities within higher education programs are organized across time and space and how organizations of time and space are produced in educational practices. Similarly, Roehl (2012b) starts from material objects within a science classroom to examine how these objects engage students. How students as subjects are performed by materials? Roehl (2012b) then considers the relation between humans and nonhumans as mutually transformative. Otherwise said, both are co-shaped by the other.

Starting from an ethnography of practices in which humans and nonhumans are considered equally important, the question arises whether and how sociomateriality has something to add to the understanding of the school. Moreover, as we focus on the daily events through which the school transpires, a shift occurs as we no longer investigate the meaning in school but are able to focus on the meaning of school. Hence, something might be said about the specific meaning of the school as a distinct learning environment.

\section{School Practices: Sociomaterial and Discursive}

Following the aforementioned scholars, we focus on the relations and forms of (dis)connections among humans and nonhumans to tell something about daily school happenings. Everything is then considered as emerging effects of the connections between human and nonhuman elements. In other words, every-thing is understood as performed into existence and hence, as 
continually in the making. Humans and nonhumans, 'their dimensions and what they are and do, all depend on the morphology of relations in which they are involved' (Callon 1998, in Fenwick, Edwards, and Sawchuk 2011, 4). Hence, 'it assumes that nothing has reality or form outside the enactment of those relations' or connections (Law 2008, in Fenwick and Landri 2012 , 2). Inspired by sociomaterial approaches, and more specifically by one of them, ActorNetwork Theory (ANT) (Latour 1992, 2005), school practices are considered not as solely human activities, but as incessantly evolving gatherings of interdependent sociomaterial and discursive components.

The first component, sociomateriality, refers to the continuous interconnections in which both human and nonhuman 'elements put together are not fixed in shape, do not belong to a larger pre-given list but are constructed at least in part as they are entangled together' (Law 2004, in Aberton 2012, 117). Hence, the backbone of practices does not only consist of human activities but includes the incessant (dis)connection between human and nonhuman elements. Attention is then paid to the relations between social and material parts and the manner in which both subjects and objects emerge as they continuously interweave. The school is then no longer understood as a 'pre-existing object of enquiry' but is seen as emerging through the interweaving of humans and nonhumans (Fenwick and Landri 2012, 2). Hence, the school appears as a relational effect, as continually in the making, as 'performed in the processes of assembling and maintaining' both humans and nonhumans (Fenwick et al. 2011, 10).

A second, discursive component of school practices is pointed out by Kalthoff and Roehl (2011) when they refer to the significance of speech acts as they focus on the interplay of both classroom interaction and materiality. The authors state that classroom interaction and material objects should be approached as interdependent and interweaved. On the one hand for objects to be transformed into artefacts that can transfer knowledge, humans have to introduce the objects as knowledge objects by oral language and/or pointing gestures. On the other hand, the authors state that it is through the appearance, materiality and function of objects that a certain order is installed in which it is clear what can and cannot be said or done (Kalthoff and Roehl 2011). Hence, speech acts seem a crucial element in (dis)connecting human and nonhuman elements and are thus be considered part of school practices when studying the school. Schatzki (2002) makes a similar plea when stating that discursive and nondiscursive acts - sayings and doings respectively - should be equally taken into account when investigating practices. Understood as a subset of doings, sayings do not need to involve language per se: raised hand, curious glances are all regarded as doings that say something about someone and/or something. Unlike Schatzki (2002) who is foremost concerned with what is said, we are particularly interested in the doings of sayings. Literally understood as a doing, our interest lies in how sayings set someone/something in motion, how they make others - human or nonhuman - do something and as such are part of the incessantly coming and holding together of humans and nonhumans.

In this paper, we move beyond a humanist perspective within school ethnographies as attention is paid to humans and nonhumans and the sayings that occur when they come together. When considering school practices as a continuous interweaving of sociomaterial and discursive elements, the school is understood as an assemblage of these practices. Hence, with the school assemblage, we refer to the arrangement or configuration which takes shape through and as part 
of the practices which transpire in the setting of the school (Schatzki 2002). The school assemblage is then considered as a hanging together of these practices which forms some kind of - always provisional - stability and of which the particularities can be described (Latour 2005). In this paper, we study these particularities and the way in which they might stabilize momentarily in - what Latour (2003; 2010; 2013a; 2013b) calls - a regime of enunciation. Otherwise said, this paper explores whether indications exist to consider the school assemblage as a distinct regime of enunciation.

\section{The School: A Regime of Enunciation?}

Originating in semiotics, Latour $(2003 ; 2010)$ initially employed the concept to refer to a particular manner of speech, a specific way of arguing with a clear distinction between what is true and what is false. When Latour (2013a; 2003; 2010) describes science, law, politics and religion as distinct regimes of enunciation, emphasis is laid not on the content of speech, but on the manner of speech, the tone characterizing it. Hence, Latour (2010) is not concerned with speaking about science. Instead, he is interested in what speaking scientifically is about, in the scientific way of establishing things, of connecting an assemblage. Referring to music, Latour $(2011,309)$ is interested in the tonality of a musical score, 'the key in which one must prepare to play the next part'. He is then not concerned with the exact musical notes but with the overall key which outlines the boundaries in which music can be composed, using the right pitch and intervals.

When investigating science and law, Latour (2010) tries to identify the key in which a scientific or legal statement can be made, in which a scientific or legal assemblage comes to be connected. According to Latour (2010), scientists produce a solid proof within scientific articles through a series of transformations linked to one another by a chain of reasoning, e.g. from electronic microscopes to graphs and tables. Through these transformations, articles can be read as maps on which it is possible to trace the reasoning process through 'the superposition of instruments, graphs, theodolites, markers, graduations and measurements' (Latour 2010, 230) until one reaches the territory where the trail was originally picked up and where more can still be learned. In contrast, judges distance themselves from direct contact with the territory and stick to the few referential steps present within the file before them, e.g. a map, a graph, a signature, to come to an unquestionable decision, a full stop (Latour 2010) .

Starting from an interest in the school as a distinct regime of enunciation, our attention is also directed towards time and space. When considering time, clock time and socially constructed time are often presented as the dominant conceptualizations (Duncheon \& Tierney 2013). Time at school is indeed characterized by both. For the school bell works in close collaboration with the school clock to indicate both the beginning and end of the school day and each chunk of time within it. Simultaneously and in contrast to this linear and objective conceptualization of time, time is experienced in very different ways by humans, including time at school. Roughly speaking: time might fly or not. From a sociomaterial perspective time itself is not considered as a universal 'a priori' which enables humans to make sense of their surroundings. Instead, time is considered a consequence of the sociomaterial connections of which it is part 
(Kontopodis 2007; Latour 1996). Hence, no such thing as a single time exists. For there are as many times as there are different relational orderings of humans and nonhumans (Kontopodis 2007; Latour 1996; Law 2002).

Space too is not considered as simply there, 'as a static container into which teacher and students are poured, or a backcloth against which they act' (Fenwick et al. 2011, 129). Following ANT and various scholars like Law (2002), Nespor (1994), McGregor (2004) and Mulcahy (2006) space is understood as a relational effect of the intertwining of humans and nonhumas, 'as actions, verbs rather than nouns, thus pointing to the ways in which they are both performed and performative rather than simply existing (Jones et al. 2004, in Fenwick et al. 2011 p. 131). Then sociomaterial gatherings are not solely about the interconnections of humans and nonhumans but also about the enactment of multiple spatial orderings.

Hence, when exploring whether indications exists to describe the school from the perspective of a distinct regime of enunciation, attention should be paid to the specific way in which a school assemblage comes together, to the musical key of school, to the elements at stake when sayings occur, to the things called into existence as humans and nonhumans gather and the way in which they do so (Latour 2003, 2010). By extension, we focus on the time(s) and space(s) which are called into existence as they are considered as a relational effect and inherent part of the sociomaterial gatherings of humans and nonhumans.

\section{Methodology}

The empirical data presented here are considered part of a first exploratory phase of an ongoing research project on the particularity of the school. This exploratory phase has been considered as an opportunity to get acquainted with the diverse field of secondary school practices. Hence, ethnographic fieldwork (November 2012 - March 2013) was conducted in six Flemish secondary schools, including both full-time and part-time education, as well as different curricular tracks, education for newcomers and Steiner education. Within diverse secondary schools both theoretically and vocationally oriented lessons were covered, as well as different age groups. With the diversity of the educational field in mind, the observed school lessons ranged from French, mathematics and behavioural sciences to carpentry, drama and car mechanics ${ }^{4}$. In addition, this exploratory phase has been conceived as a conceptual exploration and as an attempt to elucidate the concepts involved.

As school practices are often characterized by their messiness and continuous change, a protocol was developed starting from the assumption that school practices occur through both humans and nonhumans coming together. Throughout the use of a predefined protocol, attention was paid to these gatherings of humans and nonhumans. More specifically, it concerned the materials around which gatherings took place and the position assumed by humans and nonhumans within those gatherings. This protocol should not be considered as a method, referring to a restricting rule which holds the (evaluative) criteria for the inclusion or exclusion of data. Rather than a restricting straitjacket, the protocol enables a form of attention

\footnotetext{
${ }^{4}$ The selection of specific school lessons was decided in consultation with principals and teachers.
} 
to look beyond what is expected to see (Masschelein 2006). Otherwise said, registering according to a protocol can arouse a certain attention to various aspects of practices which are not considered before. As such, it commands the gaze without prescribing what to see. Registration occurred through both textual and graphical note-taking. Overall, 39 lessons were registered. The collected data then consist of field notes, photographs ${ }^{5}$, and sketches of classrooms and the movements of humans and nonhumans. Data analysis was conducted through profound and repeated re-readings of the field notes and field sketches. Starting from a sociomaterial interest and hence an attentiveness to materials within school events, the data presented here are chosen from a rich collection of data and should be considered as illustrative but non exhaustive examples. As they focus on the sociomaterial gatherings enacted by showing the specific way in which humans and nonhumans connect and disconnect and the time(s) and space(s) which are fabricated, they allow us to explore and elucidate the specific way in which gatherings knit together in what we would like to call a pedagogical regime of enunciation.

\section{Making School Things}

When objects are considered as a relational effect of intertwining humans and nonhumans and the sayings that occur within this continuous (dis)connection, possibilities arise to examine when and how different objects are enacted; under which conditions they step in the limelight. Consider the following field note.

The pupils sit at their desk and prepare exercise 16 in their exercise book called 'zebra'. One pupil raises his finger and asks the teacher the meaning of the word 'sock'. The teacher walks towards the pupil, bends over, takes the sock, pulls it away from the pupil's ankle and releases it. Two seconds later, another pupil asks the teacher the meaning of the word 'sock'. The girl next to him, bends over and holds his sock for a moment after which she releases it. Meanwhile, the teacher reaches the pupil, bends over, takes his sock, pulls it away from his ankle and releases it. While doing that, she says: 'This is a sock. One sock, two socks.' Meanwhile, the other pupils stopped preparing their exercise and watched the teacher, the pupils and socks involved. (December 6 ${ }^{\text {th }}, 2012$ )

Unnoticed before, this ordinary left sock steps in the limelight as it is grasped by the teacher who simultaneously states that this particular piece of garment is a sock. One sock, two socks. When nominated as such, this sock does not appear as an object to warm feet. Released from its ordinary use, this sock only refers to itself; one sock, two socks. Only present throughout and as part of this particular gathering in which the pupil, the teacher, fellow pupils, 'Zebra', pulling gestures and a nomination come together, this sock appears as a relational effect $-\mathrm{a}$

\footnotetext{
${ }^{5}$ Due to privacy concerns of the pupils involved, graphical note-taking through photographs was restricted to one lesson. Similar to sketching classroom maps, photographs were taken to capture the position of both humans and nonhumans.
} 
thing - isolated from its ordinary use. Unlike other socks ${ }^{6}$, this particular left sock comes into being as a thing as soon as it is entangled with other humans and nonhumans. As it is pointed at, nominated - this is a sock - and grammatically dissected - one sock, two socks -, a particular gathering is enacted in which the possibility emerges to get to know this sock, to investigate it, to study it. Roehl $(2012 \mathrm{~b}, 55)$ speaks of epistemic configurations as 'sociomaterial assemblages in which material objects are employed as epistemic objects that mediate disciplinary knowledge'. Knowledge then emerges as a relational effect when various humans and nonhumans intertwine and hold together. Hence, it is not the sock that holds the knowledge but the specific interconnection of the sock, the pupil, his fellow pupils, the teacher, 'Zebra' and the sayings that occur within this interconnection.

When entering a car workshop at school, several dismantled cars seem to await a last ride to the junkyard. However, one car of which the essentials - wheels, doors, brakes - are missing, is assigned to two pupils as they are instructed to repair the clutch. Although unlikely that this car will ever drive again, the pupils start to work on the engine as it appears to be a crucial element to fix the clutch.

The engine of a wrecked car is removed and moved by two pupils using a tackle. After arriving at the nearest bench, the engine is placed on it while it remains fastened to the tackle. As the pupils are asked to repair the clutch, they move up and down between the engine and their tool box while barely speaking to each other. (November $12^{\text {th }}$, 2012)

As this car and particularly this engine is assigned to two pupils, it steps into the limelight. No longer there to await its final transportation to the junkyard, both the car and the engine become the centre of attention. As the tackle enables the pupils to remove the engine from the car and to explore its various elements from every possible angle, as the bench provides the engine with some stability to manipulate it and as the toolbox brings in various necessary tools to fix the clutch, the engine emerges as a thing within this particular sociomaterial gathering. Literally stripped from its ordinary use - to drive a car - this engine comes into being as a thing, only present to provide the opportunity to exercise, meaning to try and to make mistakes until one gets it right. Or - as the teacher said - 'to mess around' until certain skills are mastered.

In both the classroom and the car workshop, the opportunity is provided to study and/or to exercise as things, like the sock and the engine, appear as relational effects of specific sociomaterial gatherings and the sayings that occur when human and nonhuman elements come together and hold together. Then, neither the sock, nor the engine refer to their ability to warm feet or to drive a car respectively. Isolated from their ordinary use, they appear for the sake of knowledge and/or for the sake of exercising skills ${ }^{7}$. Further elaborating the work of Roehl (2012b), we consider these sociomaterial gatherings as 'pedagogical configurations' in which material objects are enacted as pedagogical things as they enable the possibility to study and/or

\footnotetext{
${ }^{6}$ Although unnoticed, other socks must have been present due to the wintry scenery outside. On December $6^{\text {th }}$ 2012, temperatures barely climbed above freezing point.

${ }^{7}$ A point which is also made by Masschelein and Simons (2013).
} 
to exercise. Hence, it is in front of the enacted thing that pupils are provided with the opportunity to connect with and handle the sock, the engine; to turn the thing to see it from every possible angle, to try, to fail and to try again until they get what it is about.

\section{Making School Time}

As times emerge as a result of relationality, the question arises which times are fabricated through the sociomaterial relations in the specific context of the school.

In a workplace where wood and leather are handled, five girls are gathered in between two workbenches. Four of them are seated on the workbenches and are wiggling their feet while talking and working on a wooden spoon or a piece of leather. As one girl exerts too much pressure on her spoon-to-be, she breaks it. The girl swears, jumps off the workbench, takes a new piece of wood, jumps on the workbench and starts over again. (December $14^{\text {th }}, 2012$ )

As one element, the spoon, breaks, the gathering falls apart; the handled sandpaper becomes useless, the workbench which holds the needed materials close at hand becomes redundant. With the exertion of too much pressure, the 'stop' button is hit. The gathering falls apart which consequently seems to make time stand still. Humans and nonhumans previously engaged fade into the background. When provided with a new piece of unworked wood, the sandpaper and workbench reappear into the limelight. With the reconnection of the gathering, time seems to flash back and stay back to begin anew. Hence, the crumbling and subsequent reassembling of the gathering creates a 'start over' in which it becomes possible for pupils to figure out how to proceed next, to start again, in this case by recollecting the elements needed.

Within a theatre class, one pupil is frequently interrupted and asked to recommence by her teacher as she is preparing for an evening performance.

The teacher asks the pupil to repeat the text she performed last evening and will perform again this evening. The pupil takes a chair and takes a seat. The teacher asks the student whether she sat during the performance of the previous evening. The pupil confirms this and starts with the text. After some minutes, the teacher interrupts the pupil and makes some comments. The student starts again from a certain sentence. The teacher interrupts her again. The pupil listens to the comments and continues with her performance. (February $28^{\text {th }}, 2013$ )

Throughout the repeated interruption of the teacher and the subsequent repetition of the performance, both human and nonhuman elements - the pupil, the chair, the teacher, the text, the performance of the text - remain present. Moreover, they are brought to the fore in their relation to one another as the teacher utters several questions and remarks. Did the pupil sit on the chair? When does the text need a chair, either as object to get away from, to go to or as support? With every detailed examination of the relations involved and the succeeding repetition, the relations itself seem to fortify as if a temporarily settlement is reached. 'This is 
the way to do it.' Simultaneously and with every examination, time seems bracketed as if the 'repeat' button is hit to reconsider the elements involved. Hence, every 'repeat' does not only involve a fortification of the relations at hand but as such enables both the teacher and the pupil to get acquainted again with the knowledge and skill of performing this particular text.

As pupils prepare an interview with one of the school staff, gatherings neither seem to fall apart nor are they interrupted by remarks.

When two pupils each start to prepare an interview with the security officer of the school, each pupil asks the teacher the same questions, studies the same documents and uses the same software. When a third student starts to prepare his interview and asks the teacher for help, the teacher refers to one of his female colleagues working on the task. After one of the girls has passed on the documents she used, the third student begins to write (November $29^{\text {th }}, 2012$ ).

While asking the teacher the same questions, similar tools become gathered around the pupils involved: a document concerning practical guidelines in case of fire, a laptop on which Microsoft Word is running, pens and paper to write on. Although working alone, the pupils involved with the task ask each other for help or steal glances at each other's work. As such several sociomaterial gatherings emerge which contain the same elements while simultaneously sharing some elements, like the practical guidelines in case of fire. Throughout the multiplication of several similar gatherings, each gathering itself seems to fortify. For the sharing of elements, either human or nonhuman, does not seem to cause a single gathering to fall apart. As similar gatherings multiply, time itself seems to duplicate with each new gathering involved. Hence, parallel tracks of time emerge in which pupils are able to work at their own pace without being deprived of each other's help to bring the task at hand to a favourable conclusion.

As gatherings crumble, (re)connect, (re)arrange and multiply, temporal orderings seem to emerge which enable pupils to fail and try again, to think over the previous and following steps. Through the enactment of these temporal orderings pupils are presented with the possibility to study and/or exercise. One might engage with the gathering at hand and the knowledge and skills attributed to it in order to get familiar with the subsequent steps of a task, to get lost and found in search for the right way to perform, either through the rewinding, the repeating or the duplication of time.

\section{Making School Space}

The enactment of space, more specifically the enactment of regions, as a result of the continuous (dis)connection of humans and nonhumans has been explored by many researchers and has been described as an ordering of different areas set apart from one another by clear boundaries (Law and Mol 2001; Law 2002; Mol and Law 1994; Sørensen 2007). The enactment of space, more specifically regionality, through the gathering of humans and nonhumans becomes 
particularly apparent when a room ${ }^{8}$ within the school building is used both as a classroom (Figure 1) and a school restaurant (Figure 2): three demarcations are observed.

Insert Figure 1: The classroom

Insert Figure 2: The school restaurant

A first demarcation is established when humans and nonhumans come together in a peculiar way. As the pupils enter the room, tables and chairs are arranged in such a way that the whiteboard (rectangle) occupies a central place in the visual field of the pupils (quadrangles). Although the room is filled with tables and chairs, the pupils take place at those seats which enable them to see the whiteboard. In contrast to the teacher (circle) who chooses the table and chair from which she can overview all pupils present and can easily access the whiteboard. Although her table and chair only differ from others by their position in relation to the pupils and the whiteboard, two separate regions seem to emerge: a teacher's region and a pupils' region. Positioned opposite one another, the pupils cannot avoid the sight of the blackboard and teacher's desk while the teacher has a grandstand view of everyone.

A second demarcation comes to the fore when the agenda for today's lesson is written on the whiteboard. While the teacher uses a whiteboard marker, pupils take out a pencil to copy the agenda within their paper school diary. For pupils do not possess a whiteboard marker as they rarely write on the whiteboard. As Sørensen (2007) indicates, the whiteboard is part of the teachers' home as she writes more often on it than pupils do. Hence, different (socio)materials - marker and whiteboard vs. pencil and agenda - and different interactions - writing on the blackboard vs. copying from the blackboard - set the boundaries and as such create the teacher's region and the pupils' regions.

During the lessons observed within this classroom arrangement, a third demarcation is performed not by crossing boundaries as Sørensen (2007) indicates, but by not crossing them. Neither the pupils, nor the teacher leaves his/her region. The pupils remain seated, as if they are glued to their chair, and do not enter the region around the whiteboard and the teacher's desk. The teacher too seems restricted to her 'own' region, as if a rubber band only gives her a limited freedom of movement between her desk and the whiteboard. In line with Roehl (2012b), it could be argued that technology like the whiteboard, tables, chairs and their specific arrangement, enables humans to do certain things while preventing other happenings from occurring. Moreover, it is throughout the arrangement of sociomaterials and the enactment of various demarcations that a 'class'room is constructed within this particular room.

As the arrangement changes, various demarcations start to crumble leading towards the extinction of the 'class'room. When all tables close to the whiteboard are moved away from the board and several chairs are added, the pupils and the teacher are no longer positioned opposite one another. Both regions seem to evaporate further as they are no longer occupied by their inhabitants. Instead, the teacher and the pupils flow unrestricted through - what has become the restaurant.

\footnotetext{
8 This particular room contains a whiteboard, rectangular and round tables, chairs, a fully equipped bar, a fireplace, four doors, atmospheric lighting and plants.
} 
Hence, school space seems to be enacted when both humans and nonhumans come together in a particular way creating regions characterized by opposite positions, different (socio)materials and interactions and restricted boundary crossing.

An alteration of this relational pattern occurs within a car workshop at school where pupils are assigned various cars or car components. As two pupils concentrate on a car, two other pupils work on the engine of a wrecked car and one pupil balances a car tyre, no one leaves his car (component) (November $27^{\text {th }}, 2012$ ). Again, boundaries are enacted as pupils seem fixed by a rubber band, holding them near the car (component) and only giving them a limited freedom of movement around it. When they are in need of the teacher, they do not set out to search him but wait near their car until the teacher notices them and comes over, crossing the boundary without hindrance. Repeatedly crossing boundaries the teacher seems to possess a go-as-you-please ticket to join any gathering in order to correct, to reprimand or to hint at the next step. At the same time, the teacher seems deprived of a 'home' of his own, leaving him to wander about and to employ the materials assigned to the pupils.

Throughout different sociomaterial configurations and the act of (not) crossing certain boundaries, a region is enacted in which the opportunity arises to concentrate on the work at hand. As if pupils (and teachers) are restricted by a rubber band, regions seems capable of keeping out disturbing influences. For guests only arrive within one's region (or 'home') at invitation or - when entering uninvited - in order to improve one's work. Hence, boundaries are crossed to help pupils get on with the task as hand, to focus on the particular features of objects before them. As such, the intrusion of the teacher or fellow pupils enables the gathering to hold together as pupils are repeatedly pointed towards the objects at hand, making them appear again as pedagogical things, present to study them or to exercise with/on them.

\section{A Pedagogical Regime of Enunciation?}

Throughout observations and in line with Law (2002), things, time(s) and space(s) are discerned as they are enacted through a specific sociomaterial gathering. As shown, both knowledge and skills manifest themselves as a relational effect of these pedagogical configurations. Moreover, the coming and especially the holding together of humans and nonhumans, provide pupils with the opportunity to study and/or to exercise as they engage with the pedagogical things in front of them. Stripped from their ordinary meaning, these pedagogical things present themselves for the sake of knowledge, for the sake of exercising skills as pupils can try (seemingly) infinitely until they get it right. Hence, our attention should turn to this holding together or momentarily consolidation of the elements involved. Our focus then shifts from listing the human and nonhuman elements to the specific way in which these elements relate to one another, to the attempts these elements undertake to hold together, 'to ensure its subsistence' (Latour 2013b, 61). As it points towards the interactions of humans and nonhumans and the resulting time(s) and space(s) which are enacted to assure the - long enough - consolidation of the gathering at hand, we will investigate whether enough indications do exist to speak of a distinct, pedagogical 
regime of enunciation within the school. Although it is too early for final conclusions some interactions can be highlighted on the bases of the fieldwork presented here.

A first 'interaction' which contributes to the subsistence of the gathering involved seems to be the nomination of things; the act of pointing things out while simultaneously uttering what they are.

After discussing a movie about Beethoven (the composer), the teacher plays a part of a sonata at the piano. When she is finished, she asks the pupils to mention the different parts of the sonata. The pupils leaf through their musical score. Each answer is followed by a detailed elaboration of the teacher and is written down on the blackboard. Some pupils mumble in recognition. When the different parts are identified, the teacher indicates that they will listen to the sonata, performed by an orchestra, for the first time and she orders the pupils to indicate certain things on their musical score. The sonata starts. All pupils are bent over their desks. They turn pages almost simultaneously. Some pupils leaf backward as if they are looking for something, look at their neighbours and leaf forward until they reach a certain page. (...) During the performance, the teacher says things like: 'female theme, male theme'. (February $28^{\text {th }}$, 2013)

By asking pupils to indicate certain features on their musical score, the gathering holds together as pupils are bent over their desk. As the teacher plays the piano and listens to the performance, she nominates several specific characteristics of the sonata: 'female theme, male theme'. As she points ostentatiously at these features, she manages to draw in all pupils, musical scores and pencils present. By nominating specific features - 'female theme, male theme' or as presented earlier 'This is a sock. One sock, two socks' - things are not only stripped from their ordinary use, they simultaneously present the gathering involved to get familiar with its specific characteristics. The opportunity arises to dissect this gathering before it falls apart. Nominating things creates a little 'pause' in which a particular feature is put forward to stress its importance, to make sure everyone has noticed.

In a second instance, the temporal orderings enacted - start over, repeat, parallel track - seem to add to this 'pausing' mechanism. For the times enacted seem to buffer the penetration of other temporal orderings. For example, commoditized time, described by Duncheon and Tierney (2013) and Adam (2006) as a time in which efficiency, effectiveness and profitability reign to achieve a maximum output in a minimum of time. This commoditized time seems absent at first sight when pupils repeatedly start over until they get it (sort of) right or engage with the same task individually all at once. One might find more effective, efficient or profitable ways of using one's (objective) time. In addition, the 'pause' created seems fortified by the enacted spatial orderings or regions. As traffic between regions is limited and particularly motivated by the improvement or completion of one's task, outside influences and/or disturbances are momentarily suspended. The enactment of time(s) and space(s) should then be considered as an important part of a regime of enunciation since it contributes to the specific way in which a gathering is becoming - momentarily - stabilized. 
At last, a comparison with the scientific and legal regime of enunciation identified by Latour allows us to further explore the specificity of the regime observed in the investigated practices. Whereas scientific and legal practices are described by Latour (2010) as 'please-go-ons' and 'stops' respectively, we tentatively described the investigated school practices as 'pauses'. As scientists are anxious to know more and to (please-)go(-)on continuously, they return repeatedly to the (empirical) field for answers while retracing their own or others' step. In answering new questions and providing a (more) solid proof within scientific articles, chains of reference are constructed in which each reference - be it a graph, a table, an equation - carries over 'the relevant elements of the previous layer' while simultaneously adding force to the answer or proof given (Latour 2010, 225). Hence, it is through these chains of references that scientific knowledge and 'objectivity' is constructed, and thus implying 'please-go-ons' as part of adding force to answers or proofs. In contrast, judges desire to end the discussion as they strive to reach an unquestionable decision through the establishment of perpetual references. To that end, Latour observes that judges (in the supreme court) avoid direct contact with the field through new or additional references, and instead stick to the documents within the file before them in order to come to a final decision. Hence, it is not about 'go-ons' but about 'stops', and only the few referential steps compiled within the file are taken to reach a full stop (Latour 2010). Within the investigated school practices, we observed how temporary sociomaterial gatherings have the power to have objects crystalize into pedagogical things. These things - socks, wooden spoons-to-be, car engines, sonatas - are clearly not scientific objects (appearing in a chains of references) or legal cases (articulated in documents and files). Moreover, there seems no concern to incessantly extend the field of knowledge or to end a discussion irrevocable. Instead, the emergence of these things seems to provide 'a pause', that is, in front of these things the possibility exists to try something, to fail, to try again, to get it right. In addition, the ordinary meaning of objects and their common chain of reference seems to be ruptured, or at least bracketed, in order for these (ordinary) objects to become things (to study). Unlike the scientific practices in which far away phenomena become accessible through chains of reference and in which pathways are constructed to find one's way back to the (empirical) field, school practices seem to isolate objects and turn them into things that only seem to refer to themselves, here and now, and hence, to allow students to try or attempt 'to refer' to them. Ordinary meaning seems frozen or 'paused' while at the same time and within the pedagogical configuration it becomes possible to start to refer to or to look for meaning.

In conclusion, we would like to state that indications do exist which point at a pedagogical regime of enunciation within the school. This regime, preliminary described as 'pause', is characterized by specific interactions which add to the construction of pedagogical things, a specific school time and a specific school space. Within this regime, the opportunity arises for pupils to engage with the materials at hand, to get familiar with them and/or to exercise until the necessary knowledge and/or skills are mastered. 


\section{Discussion}

In our attempt to move beyond the humanist perspective in ethnographic research, we explored school practices in secondary education starting from a sociomaterial approach and looking for an enunciation regime as elaborated by Latour (2010; 2013a; 2003; 2013b). The findings about the emergence of pedagogical things and the emergence of a specific school time and space as part of the examined pedagogical configurations, do give indications which point at a distinct enunciation regime 'within' the school.

This is a first exploration of the pedagogical regime of enunciation enacted in school practices and more detailed empirical and conceptual research is needed. In our view, this first exploration already indicates that it is possible to examine the 'life of school', adding as such to the extensive field of school ethnography. The focus on objects and subjects as both performed and performative has shown to be an apt way to move beyond the often exclusive social and symbolic ethnographic accounts of school life. Objects as such have not been bestowed with human agency nor have subjects been left unspoken. Instead, both have been considered as they come into being when relating to one another. Starting from this relational approach, temporal and spatial ordering were brought to the fore as they result from certain sociomaterial gatherings and point towards the particularity of the school. Then, it becomes clear that the school can no longer be considered as a static container in which pupils and teachers make sense of their surroundings. When withdrawing from such a perspective and starting from a sociomaterial approach, the school comes to the fore as a result of the continuous fabrication of things, time(s) and space(s) and hence as continuously in the making, as having a life which cannot be traced to its inhabitants alone. When attention is paid to verbs, to interactions and the emergence of things, time(s) and space(s), important questions could be answered, not about the livability at school (life in school) but about the viability of school (life of school; how the school emerges and momentarily stabilizes. Otherwise said, how the school comes to life and tries to stay alive .

In addition, the research presented here clarifies that it is possible to examine the particularity of the school while considering both materials and classroom interaction. Materiality should then not only be regarded as something talked about, nor does it solely act as a background which renders utterances comprehensible (Roehl 2012b). Instead, materiality and classroom interaction are to be considered interdependent and interweaved as utterances appear as a crucial element to bring together and hold together gatherings of humans and nonhumans. More than an analysis of the materiality of school education and/or classroom discourse, an analysis of the enunciation regime provides a way to establish a more differentiated portrait of the specificity of the school. For that, it is not only meaningful to contrast possible 'pedagogical' regimes of enunciation with legal, scientific, political regimes as explored in the previous paragraphs. It is equally relevant to contrast typical school and classroom settings with settings that have some affinity yet could be rather different in socio-material set-up and discursive patterns. A comparison between the school restaurant where pupils learn to wait tables and a private restaurant could be rather helpful, or a comparison between a car workshop in a school and a private one. For though such practices might seem similar, the elements at stake, the things called into existence as well as the 'pauses' might be different. 


\section{References}

Aberton, Helen. 2012. "Material Enactments of Identities and Learning in Everyday Community Practices : Implications for Pedagogy." Pedagogy, Culture \& Society 20 (1): 113-136.

Adam, B. 2006. “Time.” Theory, Culture \& Society 23 (2-3): 119-126. doi:10.1177/0263276406063779.

Ball, S. 1984. "Banding, Identity and Experience.” In Life in School: The Sociology of Pupil Culture, edited by Martyn Hammersley and P Woods, 23-44. Milton Keynes: Open University Press.

Ball, Stephen. 1981. Beachside Comprehensive: A Case-Study of Secondary Schooling. Cambridge: Cambridge University Press.

Duncheon, J. C., and W. G. Tierney. 2013. "Changing Conceptions of Time: Implications for Educational Research and Rractice." Review of Educational Research 83 (2): 236-272. doi:10.3102/0034654313478492.

Fenwick, Tara, Richard Edwards, and Peter Sawchuk. 2011. Emerging Approaches to Educational Research: Tracing the Sociomaterial. Abingdon: Routledge.

Fenwick, Tara, and Paolo Landri. 2012. "Materialities, Textures and Pedagogies: SocioMaterial Assemblages in Education." Pedagogy, Culture \& Society 20 (1): 1-7.

Gordon, D. 1997. "Hidden Curriculum.” In International Encyclopedia of the Sociology of Education, edited by L J Saha, 484-487. Oxford: Pergamon.

Hammersley, Martyn. 1984. "Introduction: Reflexivity and Naturalism in Ethnography." In The Ethnography of Schooling: Methodological Issues, 1-18. Driffield: Nafferton Books.

Hammersley, Martyn. 1990. Classroom Ethnography: Empirical and Methodological Essays. Buckingham: Open University Press.

Hammersley, Martyn, and P Woods. 1984. Life in School: The Sociology of Pupil Culture. Milton Keynes: Open University Press.

Hargreaves, D.H. 1967. Social Relations in a Secondary School. London: Routledge and Kegan Paul.

Kalthoff, Herbert, and Tobias Roehl. 2011. "Interobjectivity and Interactivity: Material Objects and Discourse in Class." Human Studies 34 (4): 451-469. doi:10.1007/s10746011-9204-y.

Keddie, Nell. 1972. “Classroom Knowledge.” In Knowledge \& Control. New Directions for Sociology of Education, edited by M Young, 133-160. London: Collier-MacMillan Publishers.

Kontopodis, Michalis. 2007. "Fabrication of Times and Micro-Formation of Discourse at a Secondary School." Forum Qualitative Sozialforschung/Forum: Qualitative Social Research 8 (1).

Latour, Bruno. 1992. "Where Are the Missing Masses? The Sociology of a Few Mundane Artifacts." In Shaping Technology Building Society: Studies in Sociotechnical Change, edited by Wiebe E Bijker and John Law, 225-258. Cambridge: MIT Press.

Latour, Bruno. 1996. "Trains of Thought: Piaget, Formalism and the Fifth Dimension." Common Knowledge 6 (1): 170-191.

Latour, Bruno. 2003. "What If We Talked Politics a Little?" Contemporary Political Theory 2 (2): 143-164. doi:10.1057/palgrave.cpt.9300092.

Latour, Bruno. 2005. Reassembling the Social: An Introduction to Actor-Network Theory. Oxford: University Press.

Latour, Bruno. 2010. The Making of Law: An Ethnography of the Conseil D'état. Cambridge: Polity Press. 
Latour, Bruno. 2011. "Reflections on Etienne Souriau's Les Différents Modes D'existence." In The Speculative Turn: Continental Materialism and Realism, edited by Graham Harman, Levi Bryant, and Nick Srnicek, 304-333. Melbourne: re.press.

Latour, Bruno. 2013a. Rejoicing. Or the Torments of Religious Speech. Translated by Julie Rose. Cambridge: Polity Press.

Latour, Bruno. 2013b. An Inquiry into Modes of Existence: An Anthropology of the Moderns. Cambridge: Harvard University Press.

Law, John. 2002. "Objects and Spaces.” Theory, Culture \& Society 19 (5/6): 91-105.

Law, John, and Annemarie Mol. 2001. "Situating Technoscience: An Inquiry into Spatialities.” Environment and Planning D: Society and Space 19 (5): 609-621. doi:10.1068/d243t.

Masschelein, Jan. 2006. "Laat Ons Gaan.” In Europa Anno 2006: E-Ducatieve Berichten Uit Niemandsland, edited by Jan Masschelein and Maarten Simons, 35-45. Leuven/Voorburg: Acco.

Masschelein, Jan, and Maarten Simons. 2013. In Defence of the School: A Public Issue. Leuven: E-ducation, Culture \& Society Publishers.

McFadden, M G, and J C Walker. 1997. "Resistance Theory." In International Encyclopedia of the Sociology of Education, edited by L J Saha, 97-102. Oxford: Pergamon.

McGregor, Jane. 2004. "Spatiality and the Place of the Material in Schools." Pedagogy, Culture \& Society 12 (3): 347-372. doi:10.1080/14681360400200207.

Mifsud, Louise. 2014. "Mobile Learning and the Socio-Materiality of Classroom Practices." Learning, Media and Technology 39 (1): 142-149. doi:10.1080/17439884.2013.817420.

Mol, Annemarie. 2002. The Body Multiple: Ontology in Medical Practice. Durham: Duke University Press.

Mol, Annemarie, and John Law. 1994. "Regions, Networks and Fluids : Anaemia and Social Topology." Social Studies of Science 24 (4): 641-671. http://www.jstor.org/stable/370267.

Mulcahy, Dianne. 2006. "The Salience of Space for Pedagogy and Identity in Teacher Education: Problem-based Learning as a Case in Point." Pedagogy, Culture \& Society 14 (1): 55-69. doi:10.1080/14681360500487827.

Nespor, Jan. 1994. Knowledge in Motion: Space, Time and Curriculum in Undergraduate Physics and Management. London: The Falmer Press.

Nohl, A-M. 2011. Pädagogik Der Dinge. Kempten: Klinkhardt.

Roehl, Tobias. 2012a. "Disassembling the Classroom - an Ethnographic Approach to the Materiality of Education." Ethnography and Education 7 (1): 109-126. doi:10.1080/17457823.2012.661591.

Roehl, Tobias. 2012b. "From Witnessing to Recording - Material Objects and the Epistemic Configuration of Science Classes.” Pedagogy, Culture \& Society 20 (1): 49-70. doi:10.1080/14681366.2012.649415.

Röhl, Tobias. 2013. Dinge Des Wissens: Schulunterricht Als Sozio-Materielle Praxis. Stuttgart: Lucius \& Lucius.

Schatzki, Theodore. 2002. The Site of the Social: A Philosophical Account of the Constitution of Social Life and Change. Pennsylvania: Pennsylvania State University Press.

Sørensen, Estrid. 2007. "The Time of Materiality." Forum: Qualitative Social Research 8 (1).

Sørensen, Estrid. 2009. The Materiality of Learning: Technology and Knowledge in Educational Practice. Cambridge: University Press.

Turner, J H, and D E Mitchell. 1997. "Contemporary Sociological Theories of Education.” In International Encyclopedia of the Sociology of Education, edited by L J Saha, 21-33. Oxford: Pergamon.

Willis, Paul. 1988. Learning to Labour: How Working Class Kids Get Working Class Jobs. 
Hampshire: Gower. 
Figure 1: The classroom.

Figure 2: The school restaurant. 